\title{
GRADIENT COMPOSITE COATINGS FOR WORKING SURFACES OF BRAKING DEVICES
}

\author{
Mykhaylo Pashechko ${ }^{1 *}$, Myroslav Kindrachuk², Ihor Humeniuk ${ }^{3}$, Taras Berezhanskyi ${ }^{4}$ \\ 1 Department of Fundamentals of Technology, Lublin University of Technology, Nadbystzrycka 38, 20-618 \\ Lublin, Poland \\ 2 Engineering Department, National Aviation University, Kyiv, Ukraine \\ ${ }^{3}$ Doctoral student at the National Aviation University, Kyiv, Ukraine \\ ${ }^{4}$ Department of Monitoring and Fire Prevention, Lviv State University of Life Safety, Kleparivska 35, Lviv 79007, \\ Ukraine \\ * Corresponding Author's e-mail: mpashechko@hotmail.com
}

Received: 2017.04 .26

Accepted: 2018.05.07

Published: 2018.06.01

\begin{abstract}
In this paper a study to develop a composite wear-resistant coatings for application to the working surface of linings of brake devices, which is based on a rule of a positive gradient of mechanical properties was carried out. These devices and so coatings work in conditions of rapid rise of temperature. Thermal properties of matrix and inclusions should not differ a lot. Otherwise this will cause internal cracking and deterioration of coating. With this purpose we did the analyses of thermal properties of matrix and carbide particles of coating and concluded thet a material with balanced composition based on thermal properties will have the best wear resistance It was created and tested eutectic composites based on alloy steel 12X18H9T based on thermal characteristics of all components. Wear tests indicated the best wear resistance of coating with composition: steel 12X18H9T (matrix) - 75\%; fillers $\mathrm{TiB}_{2}-10 \%$, VC $-15 \%$.
\end{abstract}

Keywords: coating, eutectic, plasma, composite, friction, surface.

\section{INTRODUCTION}

Friction materials used in dynamic friction devices, which include brake pads, special support slipping, clutches, variators. These devices are designed to break up (clutch) and stop (brakes, sliding slip resistance) transport machines and drives for process equipment (different friction clutches and regulators) and the transmission and to change the direction of motion.

To achieve high and stable friction coefficient the intermediate layer should have specific heterogeneous structure and properties would provide a large coefficient of internal friction at high temperatures and prevent damage to the friction surface of the material.

However, there are theoretical and experimental study of the effect of temperature and temperature gradients on the friction and wear of friction pairs for various purposes $[3,6,8]$. In addition to direct effects of temperature on the wear, friction factor, theoretically and experimentally, it was found that the coefficient of friction increases with increasing temperature gradient and a decrease in overall temperature in friction. Also other authors have researched in similar field [1, $2,11,14]$.

In this regard, there is scientific and applied interest in creating composite friction materials and coatings that would allow strong thermal control. Eutectic composite alloy as the matrix use a $12 \mathrm{X} 18 \mathrm{H} 9 \mathrm{~T}$ austenitic steel. As the reinforcing phase are the most heat-resistant and wearresistant carbides and borides were used.

The objects of the study were composites based on alloys steel 12X18H9T, which include borides of titanium and chromium (HTN), borides of titanium and vanadium carbide (VTN). 
The chemical and phase composition of the alloys are given in Table 1, thermal properties in the Table 2 [4].

\section{STRUCTURE AND PROPERTIES OF PLASMA COATINGS}

For coating powders of eutectic alloy of two systems: VTN and HTN [2] were used. In sputtered eutectic coatings 'white' areas were observed, white layers, partially melted or unmelted powder and a small amount of pores (Fig. 1).

\section{EXPERIMENTAL PROCEDURE}

Tests on the friction and wear were performed on a friction machine M22-M, which allows in the process the experiment to automatically record basic characteristics of friction and wear (linear wear of friction pair) without notables model of it. As counter body the rollers of diameter $40 \mathrm{~mm}$, made of cast iron MF-15-32 were used. At a distance of $0.5 \mathrm{~mm}$ from the surface of friction of the sample introduced chromyl-koppel thermocouple, which allows to control temperature change in the friction zone and to fox the stabilization of friction and wear. Test specimens with coatings was carried out in terms of friction without lubrication by the scheme 'shaft-plane' and the load was $\mathrm{P}=20 ; 40 ; 60 ; 150 \mathrm{~N}$, sliding speed $\mathrm{V}=0.1-$ $2.0 \mathrm{~m} / \mathrm{s}$. Friction distance $\mathrm{L}=1 \mathrm{~km}$ [11].

The chemical composition and structure of the components of the surface layer formed as a result of tribological interactions were determined by X-ray analysis with the use of REMMA-106N microscope-microanalyzer [5].

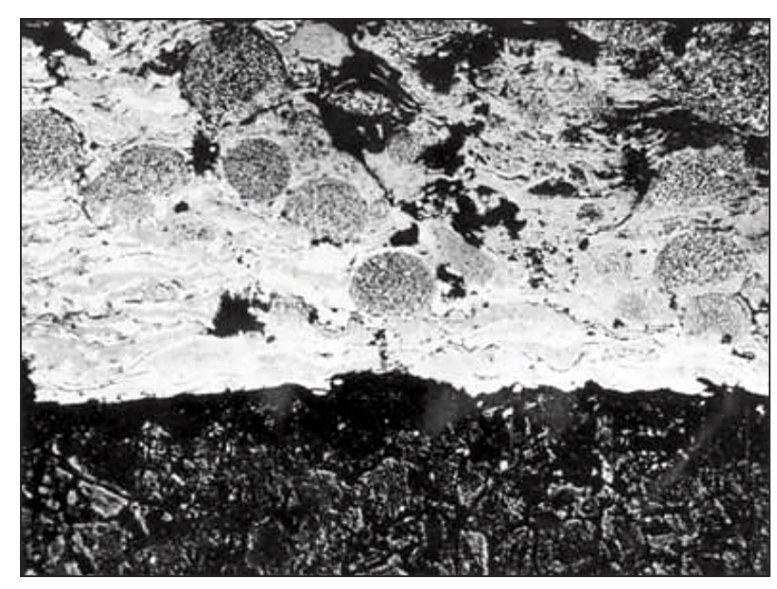

Fig. 1. Microstructure of plasma coating VTN; x500

\section{RESULTS AND DISCUSSION}

The cross-section micrographs of tested friction samples shows that the friction surface coating VTN have areas with eutectic structure (Fig. 2a). They determine the amount of wear and wear rate dependence on the specific load. Lots of white layers placed between the eutectic areas, due to the low ductility and lack of cohesion spall out from the surface.

Battered solid white layer, getting in the zone of friction, act as an abrasive (Fig. 2b) with this enhancing wear. Brittle fracture at the surface friction explicit plasma coating HTN. Specific loads of $8 \mathrm{MPa}$ bursting of the coating are typical phenomena. Tribological properties of plasma sputtered UC depend on load and temperature determined by the degree of non-equilibrium condition, porosity and adhesive-cohesive strength. Normal plasma friction coating operation is observed in a narrow range of loads and temperatures. If the load $\mathrm{P}>5 \mathrm{MPa}$, there is an intensi-

Table 1. Chemical and phase composition of eutectic alloys

\begin{tabular}{|c|c|c|c|c|c|c|c|c|c|c|c|}
\hline \multirow[b]{2}{*}{ Alloy } & \multicolumn{7}{|c|}{ Chemical composition, \% } & \multicolumn{2}{|c|}{ Phase composition } & \multirow{2}{*}{$\begin{array}{c}\text { Hardness, } \\
\text { HB }\end{array}$} & \multirow{2}{*}{$\begin{array}{l}\text { Melting } \\
\text { point, } \mathrm{K}\end{array}$} \\
\hline & $\mathrm{Cr}$ & $\mathrm{Ni}$ & $\mathrm{Ti}$ & V & $B$ & C & $\mathrm{Fe}$ & Matrix & $\begin{array}{l}\text { Hardening } \\
\text { element s }\end{array}$ & & \\
\hline BTH & 15.4 & 0.7 & 3.2 & 8.1 & $1 ., 4$ & 1.9 & 62.3 & \multirow{2}{*}{ 12X18H9T } & $\mathrm{TiB}_{2}+\mathrm{VC}$ & 470 & 1460 \\
\hline XTH & 20.5 & 8.6 & 2.5 & - & 2.6 & - & 65.8 & & $(\mathrm{Ti}, \mathrm{Cr}) \mathrm{B}_{2}$ & 370 & 1490 \\
\hline
\end{tabular}

Table 2. Thermal properties of the alloy components

\begin{tabular}{|c|c|c|}
\hline Material & Thermal Conductivity $\lambda, \mathrm{W}(\mathrm{m} \cdot \mathrm{deg})$ & Heat capacity $\mathrm{C}, \mathrm{kJ}(\mathrm{kg} \cdot \mathrm{deg})$ \\
\hline $12 \mathrm{X} 18 \mathrm{H} 9 \mathrm{~T}$ & 15.9 & 0.505 \\
\hline $\mathrm{VC}$ & 25.0 & 0.531 \\
\hline $\mathrm{TiB}_{2}$ & 21.0 & 0.636 \\
\hline $\mathrm{CvB}_{2}$ & 22.0 & 0.695 \\
\hline
\end{tabular}


a)

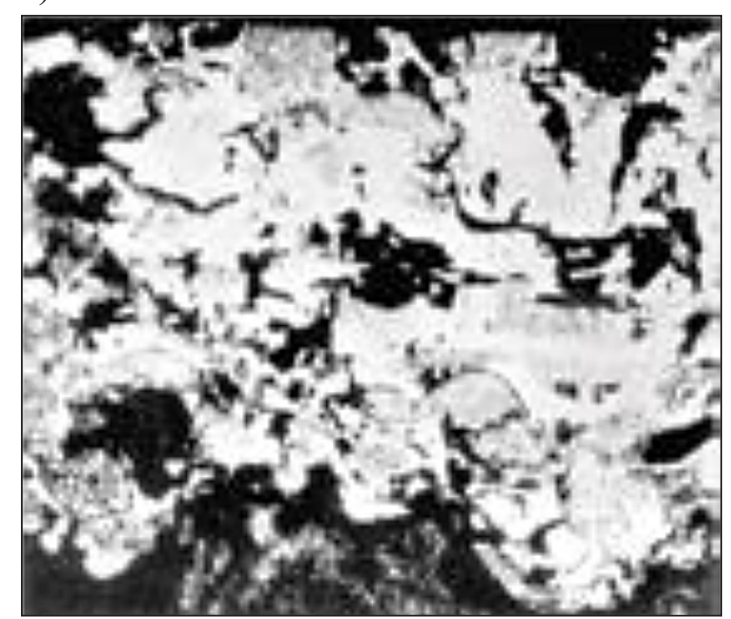

b)

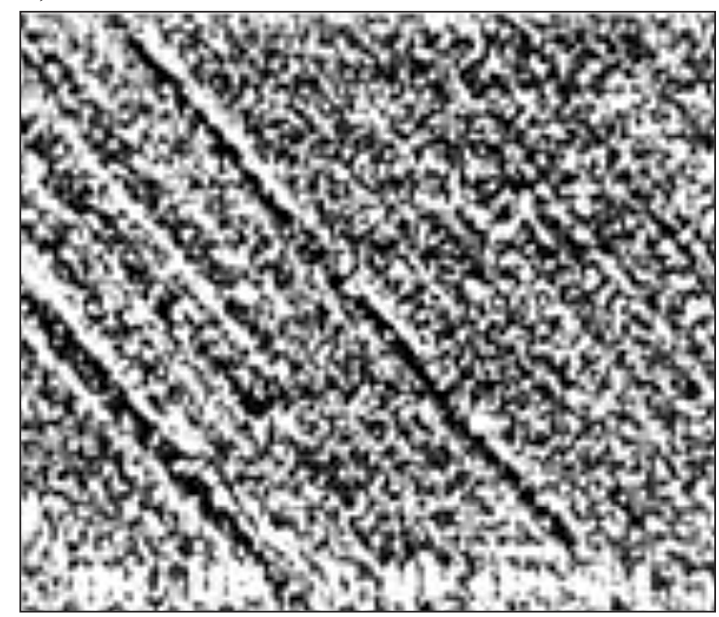

Fig. 2. Microstructures plasma coating $(a)$, x200 and the friction surface $(b)$, x500 of eutectic powder VTN

fication of wear due to brittle fracture, accompanied by chipping of elements that have abrasive properties. By elevated temperatures $(\mathrm{T}>600$ ${ }^{\circ} \mathrm{C}$ ) low durability is predetermined by decrease in hardness of the coating due to the collapse of supersaturated solid solutions and coating wears through withdrawal from the zone of friction due to loose of porous oxide films, that rapidly form on the surface of friction.

In the diffractograms of the friction surface of HTN coating reflexes of oxides $\mathrm{Fe}_{3} \mathrm{O}_{4}, \mathrm{Fe}_{2} \mathrm{O}_{3}$, $\mathrm{Cr}_{2} \mathrm{O}_{3}, \mathrm{TiO}_{2}, \mathrm{~B}_{2} \mathrm{O}_{3}$ were detected. In the coating of HTN compared with VTN coating formed larger number of oxides $\mathrm{B}_{2} \mathrm{O}_{3}$ and $\mathrm{Cr}_{2} \mathrm{O}_{3}$. Perhaps this factor, and high heat resistance is explained by the higher wear resistance of coating HTN at elevated temperatures than at lower ones. Thus, plasma coating can not realize their potential high tribotechnical properties. There is only a

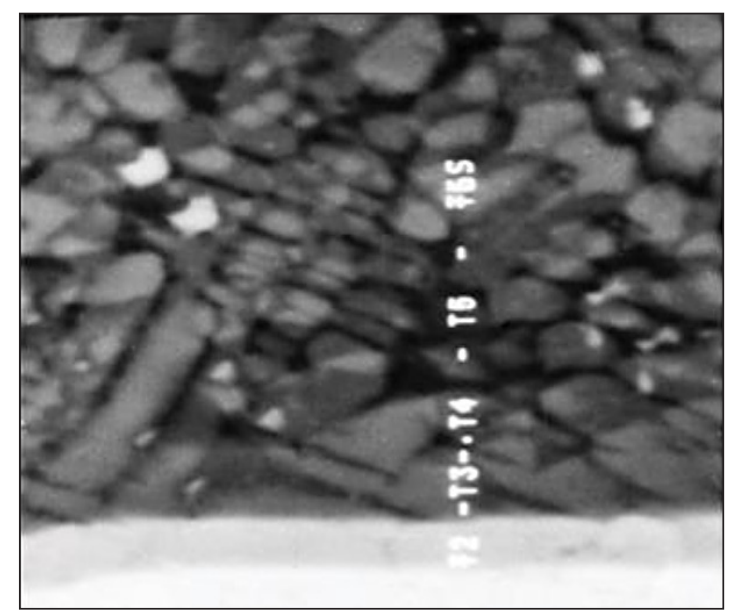

Fig. 3. Microstructure fused plasma coating VTN, $\mathrm{x} 500$ limited range of external factors in which coating workable, fair running in and form secondary structures.

Structure, mechanical properties and tribotechnical gradient of plasma coatings obtained by laser melting. Laser treatment due to its specificity (rapid heating and subsequent accelerated cooling) gives fine-dispersed structures supersaturated solid solutions and, therefore, high wear resistance of coating. Because of practical interest it is the consideration of the structural features and properties of plasma coating after processing them using laser melting.

In this mode of exposure was chosen such that the depth of penetration equal to the thickness of the applied coating or exceed it. Figure 3 presents the microstructure of plasma coating on steel $40 \mathrm{X}$, melted by the laser beam. Coating has a columnar structure - dendritic structure. Compared

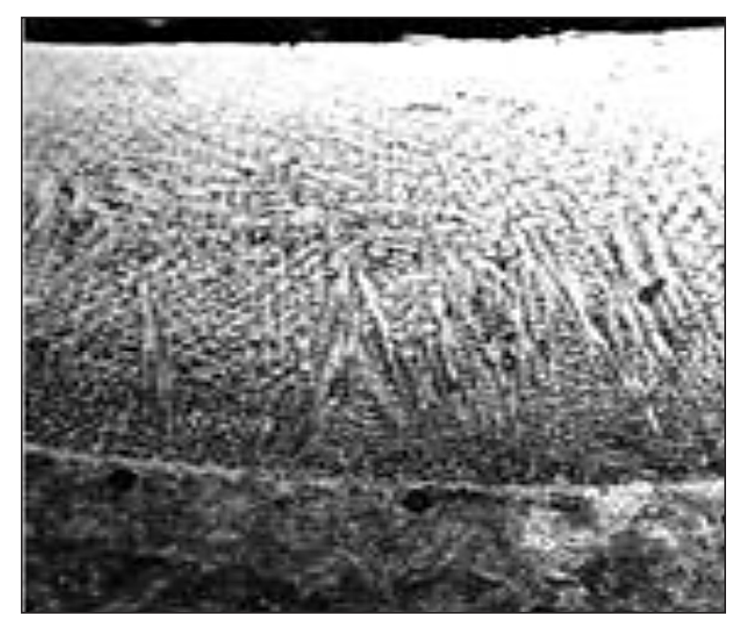

Fig. 4. Microstructure gradient plasma coating system VTN, x500 
with the initial microstructure it can be noted that the metal as a result of the concentrated radiation energy was in the liquid state. Under the influence of a large temperature gradient and the resulting high speed crystallization, the growth of dendrites principal axes held parallel to the heat sink. Note that near the surface area heat sink is less pronounced, and is parallel to the displacement of the laser beam on the surface. Thus, the orientation of dendrites in the melting zone is determined by the direction of heat.

Melting of the coating are almost $100 \%$ dence (porosity of $0.5-1.0 \%$ ), adhesion strength is increased to 400-450 MPa. The process of formation of gradient coatings obtained a patent [8]. The micrograph if the coating is shown in Figure 4. Tribological tests found increasing resistance of melted surfaces to wear compared to the original without processing more than in 2 times. Thus, if the reduced wear of sprayed coating VTN at $293 \mathrm{~K}$ is $51.1 \mathrm{mg} / \mathrm{cm}^{2} \cdot \mathrm{km}$, and of melted -27.9 $\mathrm{mg} / \mathrm{cm}^{2} \cdot \mathrm{km}$. The task was to provide a method of drawing plasma coating with high wear resistance and working in by forming its gradient structure: a thin surface layer of dispersed structure with low shear resistance and depth of the columnar structure oriented normal to the friction surface. To draw such a coating an alloy VTN of the system $12 \mathrm{X} 18 \mathrm{H} 9 \mathrm{~T}-\mathrm{TiB}_{2}-\mathrm{VC}$ was chosen, because it is more durable than the alloy HTN. Previously the optimal structure of hardening phases $\left(\mathrm{TiB}_{2}\right.$, $\mathrm{VC}$ ) on the wear resistance coatings, based on their thermal properties was investigated.
It should be noted that the decrease in wear and friction coefficient in the temperature range $300-500{ }^{\circ} \mathrm{C}$ with increasing content of vanadium carbide probably due to its ability to oxidation. Unlike the diboride of titanium, vanadium carbide under these temperature begins to oxidize. The resulting oxide film containing $\mathrm{FeO}, \mathrm{TiO}_{2}$, $\mathrm{V}_{2} \mathrm{O}_{3}, \mathrm{~B}_{2} \mathrm{O}_{3}$ serves as a solid lubricant and protect the surface from wear.

Therefore, for further research, given optimal tribotechnical properties of the coating $(\mathrm{I}, f, \Theta)$, we selected an alloy with eutectic composition with 10 vol. $\% \mathrm{TiB}_{2}$ and 15 vol. $\% \mathrm{VC}$.

Research has established that such properties as wear, the maximum surface temperature and the coefficient of friction depends on the ratio of the content of $\mathrm{TiB}_{2}$ inclusions and VC (Fig. 5). This is probably not only due to their different physicomechanical properties, but also thermophysical.

In Figure 6 the microstructure of their friction surfaces are given. By sliding speed of $0.2-0.8 \mathrm{~m} / \mathrm{s}$ (surface temperature $300{ }^{\circ} \mathrm{C}$ ) the formed secondary structure has smooth surface (Fig. $6 a$ ). With increasing sliding speed to $1.2 \mathrm{~m} / \mathrm{s}$ (temperature $400{ }^{\circ} \mathrm{C}$ ) and up to $1.6 \mathrm{~m} / \mathrm{s}$ (temperature $550{ }^{\circ} \mathrm{C}$ ) processes of friction and wear are determined by the formation of oxide films (as in Fig. $6 b$ and $6 c$ ). In the sliding speed range $1.8-2 \mathrm{~m} / \mathrm{s}$ (temperature $800-850^{\circ} \mathrm{C}$ ) occurs contact friction. Wear scars on the samples - are flows and solidified eutectic crystals (Fig. 6d). Thus there is a sharp decrease in the coefficient of friction to values characteristic to boundary friction $(0.05-0.10)$.

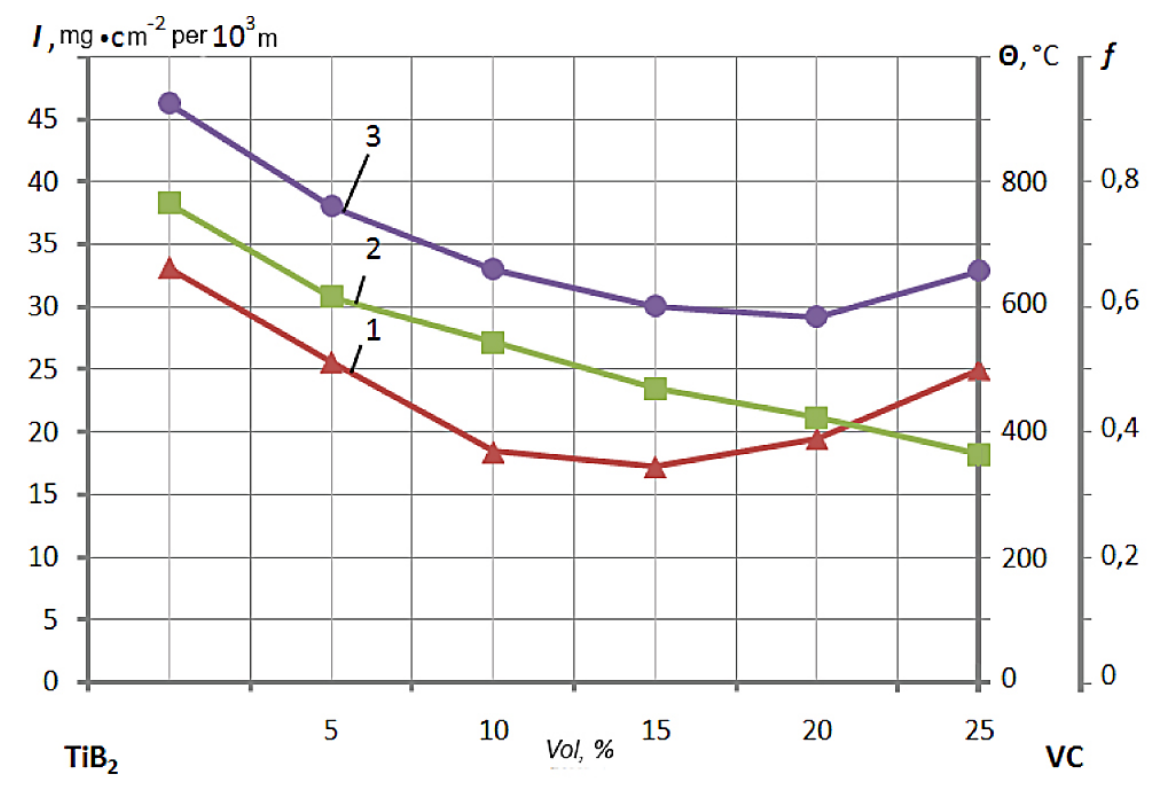

Fig. 5. Dependence tribotechnical properties melted coating VTN plasma volume content of TiB 2 and VC at $\mathrm{P}=2 \mathrm{MPa}, \mathrm{V}=0.5 \mathrm{~m} / \mathrm{s}, 1-\mathrm{f} ; 2-\Theta ; 3-\mathrm{I}$ 
a)

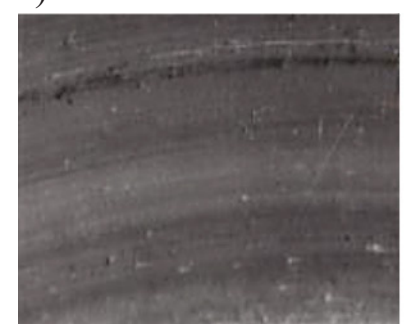

b)

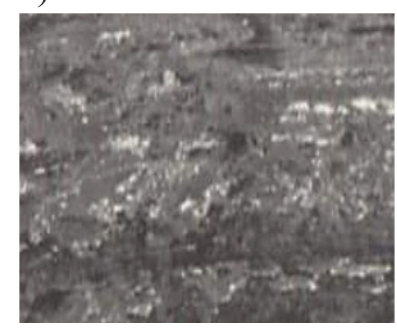

c)

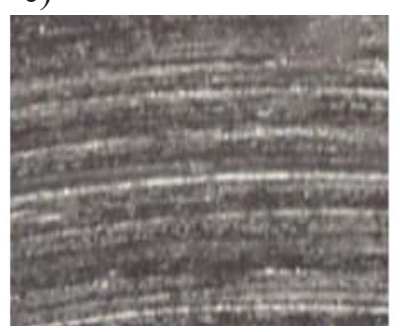

d)

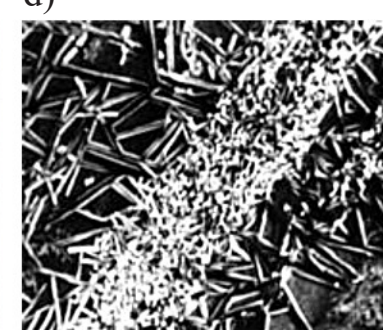

Fig. 6. Microstructure surface friction gradient coating, $\mathrm{P}=2 \mathrm{MPa}, a-\mathrm{V}-0.4 \mathrm{~m} / \mathrm{s}, \mathrm{t}-250^{\circ} \mathrm{C}$; $b-\mathrm{V}-1.2 \mathrm{~m} / \mathrm{s}, \mathrm{t}-400{ }^{\circ} \mathrm{C} ; c-\mathrm{V}-1.6 \mathrm{~m} / \mathrm{s}, \mathrm{t}-560{ }^{\circ} \mathrm{C} ; d-\mathrm{V}-2 \mathrm{~m} / \mathrm{s}, \mathrm{t}-850{ }^{\circ} \mathrm{C}$.

\section{CONCLUSIONS}

1. It was proved and experimentally confirmed the composition of the eutectic composite alloy gradient coating based on thermo physical properties of the binder and fillers (thermal conductivity, heat capacity): steel binder $12 \mathrm{X} 18 \mathrm{H} 9 \mathrm{~T}$ $-75 \%$; fillers $\mathrm{TiB}_{2}-10 \%, \mathrm{VC}-15 \%$.

2. Double fusion of plasma coatings have improved wear resistance due to its gradient structure, where the surface layer has elastic - plastic fine-grained structure contributes to running in, and is located below the layer with columnar structure efficiently damps external normal and shear loading. This increases the contact strength of the coating and reduces the friction and temperature gradient.

3. Designed coating for braking devices can be attributed to friction materials for medium friction conditions (short-term temperature up to $400{ }^{\circ} \mathrm{C}$, long - up to $250{ }^{\circ} \mathrm{C}$, pressures up to $1.5 \mathrm{MPa})$.

\section{REFERENCES}

1. Baker B.W., McNelley T.R., Brewer L.N., Grain size and particle dispersion effects on the tensile behavior offriction stir welded MA956 oxide dispersion strengthened steel from low to elevated temperatures. Materials Science and Engineering: A, 589(1), 2014, 217-227.

2. Kindrachuk M.V., Korneev V.G., Melentev O.P., Panarin V.Ye. Patent 1050179 USSR. Powder material for wear resistant coatings. USSR-3411077/27; Applied 05.03.1982; Published in 1983.

3. Frölich D., Magyar B., Sauer B., A comprehensive model of wear, friction and contact temperature in radial shaft seals. Wear, 311(1-2), 2014, 71-80.

4. Kindrachuk M., Shurin A., Panarin V., Wear resistance of stainless eutectic alloys with implantation phases. Problems of friction and wear. Technika, 19, 1981, 17-28.
5. Kindrachuk M.V., Tisov O.V., Stebeletska N.V., The development of gradient coatings for linings of braking devices. Technology Audit and Production Reserves, 3/2 (17), 2014, 7-16.

6. Kooi B.J, Pei Y.T, De Hosson J.Th.M., The evolution of microstructure in a laser clad TiB-Ti composite coating. Acta Materialia, 51(3), 2003, 831-845.

7. Alva L., Shapovalov K., Jacobsen G.M., Back C.A., Xinyu H., Experimental study of thermo-mechanical behavior of $\mathrm{SiC}$ composite tubing under high temperature gradient using solid surrogate. Journal of Nuclear Materials, 466, 2015, 698-711.

8. Kindrachuk M.V., Korbut Ye.V., Stebeletska N.M. et al., The method to produce of gradient wear resistant plasma coatings with high running-in properties. Patent 84998 of Ukraine IPC C21D1/78 (2006.01) No. 201304817; Applied 16.04.2013; Published 11.11.2013.

9. Pashechko M., Barszcz M., Eutectic alloy matrix, comprises manganese, carbon, boron, silicon, nickel, chromium, copper and iron. Patent, PL403566A1, 2016.

10. Pashechko M., Dziedzic K., Barszcz M., Study of the structure properties of wear-resistant eutectic Fe-Mn-C-B-Si-Ni-Cr coatings. Powder Metallurgy and Metal Ceramics, 52(7-8), 2013, 469-476.

11. Tisov O., New pecularities of generation of frictiou-induced leyers on the wear surface of Co-TiC cemented carbides. Problems of Tribology, 77(3), 2015, 6-13.

12. Xiawei Yang, Wenya Li, Jiang Li, Tiejun Ma, Jia Guo, FEM analysis of temperature distribution and experimental study of microstructure evolution in friction interface of GH4169 superalloy. Materials \& Design, 84, 2015, 133-143.

13. Yinghua Lin, Yongping Lei, Xueqiao Li, Xiaohui Zhi, Hanguang Fu., A study of $\mathrm{TiB}^{2} / \mathrm{TiB}$ gradient coating by laser cladding on titanium alloy. Optics and Lasers in Engineering, 82, 2016, 48-55.

14. Yuankai Zhou, Hua Zhu, Xue Zuo, Dynamic evolutionary consistency between friction force and friction temperature from the perspective of morphology and structure of phase trajectory. Tribology International, 94, 2016, 606-615. 